Research Paper

\title{
LMOI Super-Enhancer rs2168101 G>T Polymorphism Reduces Wilms Tumor Risk
}

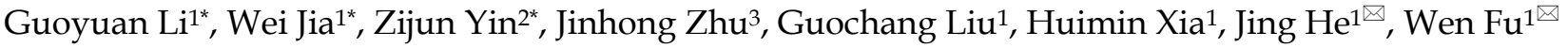 \\ 1. Department of Pediatric Surgery, Guangzhou Institute of Pediatrics, Guangzhou Women and Children's Medical Center, Guangzhou Medical University, \\ Guangzhou 510623, Guangdong, China \\ 2. Department of Oncology, The First Affiliated Hospital, Jinan University, Guangzhou 510632, Guangdong, China \\ 3. Department of Clinical Laboratory, Molecular Epidemiology Laboratory, Harbin Medical University Cancer Hospital, Harbin 150040, Heilongjiang, China \\ *These authors contributed equally to this work.
}

$\square$ Corresponding authors: Wen Fu, Department of Pediatric Surgery, Guangzhou Institute of Pediatrics, Guangzhou Women and Children's Medical Center, Guangzhou Medical University, 9 Jinsui Road, Guangzhou 510623, Guangdong, China, Tel./Fax: (+86-020) 38076154, Email: lydia_fw@hotmail.com; or Jing He, Department of Pediatric Surgery, Guangzhou Institute of Pediatrics, Guangzhou Women and Children's Medical Center, Guangzhou Medical University, 9 Jinsui Road, Guangzhou 510623, Guangdong, China, Tel./Fax: (+86-020) 38076560, Email: hejing198374@gmail.com.

(C) Ivyspring International Publisher. This is an open access article distributed under the terms of the Creative Commons Attribution (CC BY-NC) license (https://creativecommons.org/licenses/by-nc/4.0/). See http://ivyspring.com/terms for full terms and conditions.

Received: 2018.09.10; Accepted: 2019.02.23; Published: 2019.04.21

\begin{abstract}
Wilms tumor is one of the most prevalent pediatric malignancies in childhood cancer worldwide. A genome-wide association study recognized that LIM domain only 1 (LMOI) increases the risk of oncogenic potential. An association has been found that $\mathrm{LMOI}$ gene polymorphisms are associated with the susceptibility to Wilms tumor. One hundred forty-five children with Wilms tumor and 531 cancer-free children were included in this hospital-based case-control study. Five potentially functional polymorphisms in the LMOI gene (rs2168101 G>T, rs1042359 A>G, rs1 $1041838 \mathrm{G}>\mathrm{C}$, rs2071458 C>A and rs3750952 G>C) were genotyped by the TaqMan method. The association between selected polymorphisms and Wilms tumor susceptibility was measured by calculating the odds ratio (OR) and the $95 \%$ confidence interval $(\mathrm{Cl})$. Only rs2168101 $\mathrm{G}>\mathrm{T}$ polymorphism was found to have a significant protective effect against Wilms tumor (GT vs. GG: adjusted $O R=0.58$, 95\% $\mathrm{Cl}=0.39-0.88, P=0.010 ; \mathrm{GT} / \mathrm{TT}$ vs. $\mathrm{GG}$ : adjusted $\mathrm{OR}=0.67,95 \% \mathrm{Cl}=0.46-0.97, P=0.034$ ). Moreover, carriers of 3-5 protective genotypes had significantly lower tumor risk than carriers of $0-2$ protective genotypes (adjusted $\mathrm{OR}=0.62,95 \% \mathrm{Cl}=0.42-0.91, P=0.022$ ). The stratified analysis showed that the protective effect of rs 2168101 GT/TT was predominant in males, and rs 2071458 GT/TT was predominant in females. Regarding the combined risk genotypes, the analysis indicated that the 3-5 protective genotypes collectively decreased Wilms tumor risk in females. These results suggest that $L M O I$ gene rs $2168101 \mathrm{G}>\mathrm{T}$ polymorphism may help prevent Wilms tumor, but this conclusion should be verified in other populations and additional studies.
\end{abstract}

Key words: LMO1, polymorphism, Wilms tumor, susceptibility

\section{Introduction}

Wilms tumor, which is the common name for nephroblastoma, has been recognized as one of the most prevalent pediatric malignancies in childhood cancer, generally developing in children under 5 years of age and morphologically resembling embryonic kidney [1-3]. It constitutes approximately $8 \%$ of all cancers among children younger than 15 years in Western populations [4]. In Western populations, the occurrence rate of Wilms tumor is approximately
$1 / 8,000$ children [5], while the rate is approximately 3.3 cases per million in China [6]. Approximately $2 \%$ of Wilms tumor patients have a family history, and they are generally diagnosed as known causal genetic damage $[7,8]$. However, no more than $5 \%$ of cases can be attributed to known causes, and the genetic basis underlying most Wilms tumor is not well understood [9]. Therefore, for Wilms tumor prevention and early diagnosis, it is important to identify risk factors and 
biomarkers that are associated with disease susceptibility to screen high-risk populations.

Genome-wide association study (GWAS) is a useful method employed without a hypothesis to find associations between susceptible genes and complex diseases, including tumors [9]. Previous GWASs and case-control studies have discovered several inherited susceptibility genes, such as FWT1 [10], FWT2 [11], BRCA2 [12], TP53 [13, 14], BARD1 [15], CTR9 [16], hOGG1 and FEN1 [17], and XPD [18] that are significantly associated with the risk of Wilms tumor. To date, no polymorphisms within lncRNAs and Wilms tumor risk have been reported, despite their implication in carcinogenesis as either protooncogenes or an anti-oncogenes [19]. Recently, we validated a critical susceptibility gene LIM domain only 1 (LMO1) [20] in a hospital-based, case-control study with a total of 145 Wilms tumor children and 531 cancer-free children, one of the members of the $L M O$ gene super-family. The cysteine-rich transcriptional regulator is encoded by $11 \mathrm{p} 15$ in the LMO1 gene, comprising two LIM zinc-binding domains. The LMO1 gene is mainly concentrated in the nervous system and participates in the development of the nervous system [21]. Overexpression of LMO1 was initially found in patients with T-cell acute lymphoblastic leukemia [22].

In our previous study, four GWAS-identified LMO1 gene polymorphisms (rs110419 A>G, rs4758051 $\mathrm{G}>\mathrm{A}, \mathrm{rs} 10840002 \mathrm{~A}>\mathrm{G}$ and $\mathrm{rs} 204938 \mathrm{~A}>\mathrm{G}$ ) were found to be associated with Wilms tumor susceptibility, but only the rs110419 $A>G$ polymorphism may reduce the susceptibility to Wilms tumor [20]. Thus, other LMO1 gene polymorphisms require further determination to investigate Wilms tumor susceptibility. With this in mind, we carried out the current hospital-based case-control study with the same 145 Wilms tumor-bearing children and 531 cancer-free children to explore the association between five potentially functional polymorphisms in the LMO1 gene [rs2168101 G>T (a super-enhancer polymorphism identified by Oldridge et al.) [23], rs1042359 A $>\mathrm{G}$, rs11041838 G>C, rs2071458 C>A and rs3750952 G>C] and Wilms tumor susceptibility in a southern Chinese population.

\section{Materials and methods}

\section{Study subjects}

Detailed information on the recruitment criteria has been reported previously [15, 24-26]. From March 2001 to June 2016, we recruited 145 Wilms tumor patients from the Department of Pediatric Urology of the Guangzhou Women and Children Medical Center. Moreover, 531 cancer-free children from the same hospital who had undergone routine physical examinations were randomly selected as controls [27-30]. All subjects were non-individual Han genetic individuals in South China. The response rate was approximately $90 \%$ for Wilms tumor patients and 95\% for cancer-free controls. The Institutional Review Board of Guangzhou Women and Children's Medical Center approved this study, and each participant's parent or legal guardian provided medical informed consent.

\section{Polymorphism analysis}

Approximately $2 \mathrm{~mL}$ of peripheral blood was collected from each subject for DNA extraction. Five LMO1 potentially functional gene polymorphisms (rs2168101 G>T, rs1042359 A>G, rs11041838 G>C, rs2071458 C>A and rs3750952 G>C) were chosen for genotyping [31]. Genomic DNA was isolated from peripheral blood leukocytes through a TIANamp Blood DNA Kit (TianGen Biotech, Beijing, China). A 7900 Sequence Detection System (Applied Biosystems, Foster City, CA) and TaqMan real-time PCR were used in the LMO1 gene polymorphism genotyping, as described in previous articles [32-35]. To acquire reliable results, we performed the genotyping blindly without knowledge of whether the subject was a case or control subject. Moreover, $10 \%$ of the samples were selected randomly for repeated assays, and the genotype concordance was $100 \%$.

\section{Statistical analysis}

The $\chi^{2}$ test was used to compare differences in the frequency distributions of demographic characteristics between cases and controls. The Hardy-Weinberg equilibrium for the genotype frequencies in controls was detected with a goodness-of-fit $\chi^{2}$ test. To further explore the associations between LMO1 polymorphisms and Wilms tumor susceptibility, we calculated the odds ratio (OR) and the $95 \%$ confidence interval (CI) using non-conditional logistic regression and adjusting for age and gender. All tests were two-sided. $P<0.05$ was considered statistically significant. All statistical analyses were performed with SAS software (Version 9.4; SAS Institute, Cary, NC).

\section{Results}

\section{Population characteristics}

Overall, 145 patients with Wilms tumor and 531 cancer-free children were included in our analysis. The demographic characteristics of the Wilms tumor children and the cancer-free children are presented in Supplementary Table 1 . The mean age of the children with Wilms tumor was $26.17 \pm 21.48$ months, and the 
mean age of the cancer-free children was $29.73 \pm 24.86$ months. There was no significant difference in the age $(P=0.725)$ or gender $(P=0.956)$ distributions between patients and controls. According to the National Wilms Tumor Study-5 criteria [36], the clinical stages of the patients were divided into stages I-IV and 'not available', corresponding to $4(2.76 \%), 49(33.79 \%), 50$ $(34.48 \%), 33(22.76 \%)$, and $9(6.21 \%)$ cases, respectively.

\section{Associations between LMOI gene polymorphisms and Wilms tumor susceptibility}

The genotype frequencies of the five selected LMO1 gene polymorphisms and their associations with Wilms tumor susceptibility are presented in Table 1. We observed that the frequency distributions of all of the LMO1 polymorphisms were consistent with the Hardy-Weinberg equilibrium $(P=0.670$ for rs2168101 G>T, $P=0.065$ for $\operatorname{rs} 1042359 A>G, P=0.448$ for rs11041838 $G>C, P=0.911$ for rs2071458 $C>A$ and $P=0.994$ for $\mathrm{rs} 3750952 \mathrm{G}>\mathrm{C}$ polymorphism) in controls. Among the five polymorphisms, we observed that the rs2168101 G>T polymorphism corresponded to a significant decrease in Wilms tumor susceptibility (GT vs. GG: adjusted $\mathrm{OR}=0.58$, 95\% CI=0.39-0.38, $P=0.010$; and GT/TT vs. GG: adjusted $\quad \mathrm{OR}=0.67, \quad 95 \% \quad \mathrm{CI}=0.46-0.97, \quad P=0.034)$. However, no associations were found between the other four polymorphisms and Wilms tumor susceptibility. When these five polymorphisms of protective genotypes were combined, we found that the individuals with the five protective genotypes had reduced Wilms tumor susceptibility compared with those with $0-2$ protective genotypes (adjusted $\mathrm{OR}=0.64,95 \% \mathrm{CI}=0.43-0.94, P=0.022)$.

Table 1. Genotype frequencies of $L M O I$ gene polymorphisms and Wilms tumor susceptibility

\begin{tabular}{|c|c|c|c|c|c|c|c|}
\hline Genotype & Cases $(\mathrm{N}=145)$ & Controls $(\mathrm{N}=531)$ & $P$ a & Crude OR $(95 \%$ CI) & $P$ & Adjusted OR $\left(95 \%\right.$ CI) ${ }^{b}$ & $P^{b}$ \\
\hline \multicolumn{8}{|c|}{ rs2168101 G>T (HWE=0.670) } \\
\hline GG & $90(62.07)$ & $275(51.79)$ & & 1.00 & & 1.00 & \\
\hline GT & $41(28.28)$ & $217(40.87)$ & & $0.58(0.38-0.87)$ & 0.009 & $0.58(0.39-0.88)$ & 0.010 \\
\hline TT & $14(9.66)$ & $39(7.34)$ & & $1.10(0.57-2.11)$ & 0.782 & $1.14(0.59-2.20)$ & 0.702 \\
\hline Additive & & & 0.021 & $0.82(0.61-1.10)$ & 0.182 & $0.83(0.61-1.12)$ & 0.214 \\
\hline Dominant & $55(37.93)$ & $256(48.21)$ & 0.028 & $0.66(0.45-0.96)$ & 0.028 & $0.67(0.46-0.97)$ & 0.034 \\
\hline Recessive & $131(90.34)$ & $492(92.66)$ & 0.359 & $1.35(0.71-2.56)$ & 0.360 & $1.40(0.73-2.66)$ & 0.310 \\
\hline \multicolumn{8}{|c|}{ rs1042359 A>G $(\mathrm{HWE}=0.065)$} \\
\hline AA & $130(89.66)$ & 485 (91.34) & & 1.00 & & 1.00 & \\
\hline AG & $14(9.66)$ & $43(8.10)$ & & $1.22(0.65-2.29)$ & 0.547 & $1.21(0.64-2.28)$ & 0.564 \\
\hline GG & $1(0.69)$ & $3(0.56)$ & & $1.24(0.13-12.06)$ & 0.851 & $1.13(0.12-11.03)$ & 0.915 \\
\hline Additive & & & 0.822 & $1.19(0.68-2.08)$ & 0.540 & $1.17(0.67-2.04)$ & 0.582 \\
\hline Dominant & $15(10.34)$ & $46(8.66)$ & 0.531 & $1.22(0.66-2.25)$ & 0.532 & $1.20(0.65-2.22)$ & 0.561 \\
\hline Recessive & $144(99.31)$ & $528(99.44)$ & 0.862 & $1.22(0.13-11.84)$ & 0.863 & $1.11(0.11-10.84)$ & 0.927 \\
\hline \multicolumn{8}{|c|}{ rs11041838 G>C $(\mathrm{HWE}=0.448)$} \\
\hline GG & $100(68.97)$ & $386(72.69)$ & & 1.00 & & 1.00 & \\
\hline GC & $39(26.90)$ & $136(25.61)$ & & $1.11(0.73-1.68)$ & 0.634 & $1.11(0.73-1.68)$ & 0.638 \\
\hline $\mathrm{CC}$ & $6(4.14)$ & $9(1.69)$ & & $2.57(0.90-7.40)$ & 0.079 & $2.51(0.87-7.23)$ & 0.088 \\
\hline Additive & & & 0.187 & $1.26(0.89-1.79)$ & 0.194 & $1.26(0.89-1.78)$ & 0.203 \\
\hline Dominant & $45(31.03)$ & $145(27.31)$ & 0.376 & $1.20(0.80-1.79)$ & 0.377 & $1.20(0.80-1.78)$ & 0.385 \\
\hline Recessive & $139(95.86)$ & $522(98.31)$ & 0.077 & $2.50(0.88-7.15)$ & 0.087 & $2.44(0.85-6.99)$ & 0.096 \\
\hline \multicolumn{8}{|c|}{ rs2071458 C>A $(\mathrm{HWE}=0.911)$} \\
\hline $\mathrm{CC}$ & $101(69.66)$ & $324(61.02)$ & & 1.00 & & 1.00 & \\
\hline CA & $38(26.21)$ & $181(34.09)$ & & $0.67(0.45-1.02)$ & 0.062 & $0.69(0.45-1.04)$ & 0.078 \\
\hline AA & $6(4.14)$ & $26(4.90)$ & & $0.74(0.30-1.85)$ & 0.520 & $0.71(0.28-1.78)$ & 0.462 \\
\hline Additive & & & 0.159 & $0.75(0.53-1.04)$ & 0.086 & $0.75(0.54-1.05)$ & 0.090 \\
\hline Dominant & $44(30.34)$ & $207(38.98)$ & 0.056 & $0.68(0.46-1.01)$ & 0.057 & $0.69(0.47-1.03)$ & 0.067 \\
\hline Recessive & $139(95.86)$ & $505(95.10)$ & 0.703 & $0.84(0.34-2.08)$ & 0.703 & $0.79(0.32-1.97)$ & 0.619 \\
\hline \multicolumn{8}{|c|}{ rs3750952 G>C $(\mathrm{HWE}=0.994)$} \\
\hline GG & $78(53.79)$ & $253(47.65)$ & & 1.00 & & 1.00 & \\
\hline GC & $51(35.17)$ & $227(42.75)$ & & $0.73(0.49-1.08)$ & 0.117 & $0.74(0.50-1.10)$ & 0.137 \\
\hline $\mathrm{CC}$ & $16(11.03)$ & $51(9.60)$ & & $1.02(0.55-1.89)$ & 0.956 & $1.06(0.57-1.97)$ & 0.860 \\
\hline Additive & & & 0.259 & $0.90(0.68-1.19)$ & 0.446 & $0.91(0.69-1.21)$ & 0.524 \\
\hline Dominant & $67(46.21)$ & $278(52.35)$ & 0.189 & $0.78(0.54-1.13)$ & 0.190 & $0.80(0.55-1.15)$ & 0.229 \\
\hline Recessive & $129(88.97)$ & $480(90.40)$ & 0.610 & $1.17(0.64-2.12)$ & 0.610 & $1.21(0.66-2.19)$ & 0.538 \\
\hline \multicolumn{8}{|c|}{ Combined effect of protective genotypes c } \\
\hline $0-2$ & $55(37.93)$ & $146(27.50)$ & & 1.00 & & 1.00 & \\
\hline $3-5$ & $90(62.07)$ & $385(72.50)$ & 0.015 & $0.62(0.42-0.91)$ & 0.015 & $0.64(0.43-0.94)$ & 0.022 \\
\hline
\end{tabular}

${ }^{a} \chi^{2}$ test for genotype distributions between Wilms tumor patients and controls. ${ }^{b}$ Adjusted for age and gender. ${ }^{c}$ The protective genotypes were carriers with rs2168101 GT/TT, rs1042359 AG/AA, rs11041838 GC/GG, rs2071458 CA/AA and rs3750952 GC/CC genotypes. 


\section{Stratification analysis}

We performed an analysis stratified by age, gender, and clinical stages to further evaluate the combined effect of LMO1 gene polymorphisms (rs2168101 G>T and rs2071458 C>A) and the susceptibility of Wilms tumors given protective genotypes (Table 2). Compared to the rs2168101 GG genotype, the protective effect of the GT/TT genotype was more predominant in males (adjusted $\mathrm{OR}=0.50,95 \%$ $\mathrm{CI}=0.30-0.84, P=0.009$ ). Nevertheless, the rs2071458 CA/AA genotype was more predominant in females (adjusted $\mathrm{OR}=0.36,95 \% \mathrm{CI}=0.19-0.70, P=0.003$ ). In addition, the combined analysis indicated that the 3-5 protective genotypes obviously decreased Wilms tumor susceptibility in females (adjusted OR=0.55, 95\% CI=0.30-0.99, $P=0.045)$.

\section{Genotype-based mRNA expression analysis}

As shown in Figure 1, the rs2168101 G>T polymorphism was also associated with altered LMO1 mRNA expression in skeletal muscle tissues based on the public database GTEx Portal (http://www.gtex portal.org/home/) $[18,37]$.

\section{Discussion}

In the current hospital-based case-control study, we explored the association of five LMO1 gene polymorphisms with Wilms tumor susceptibility in 145 patients and 531 cancer-free controls. Although an association between LMO1 gene polymorphisms and Wilms tumor susceptibility in Chinese children has been reported by our team, there are many more LMO1 gene polymorphisms worthy of exploration. In this study, we verified that the super-enhancer rs2168101 G>T polymorphism was significantly associated with a decreased risk of Wilms tumor, which was similar to the trend for neuroblastoma [23, 31].
On the basis of GWAS research, there is growing evidence that LMO1 is a significant determinant of cancer susceptibility. Wang et al. identified that four genetic variants of LMO1 (rs110419 A>G, rs4758051 $\mathrm{G}>\mathrm{A}, \mathrm{rs} 10840002 \mathrm{~A}>\mathrm{G}$ and rs204938 A>G) contributed to tumorigenesis ability in neuroblastoma among individuals of European descent [38]. Subsequently, this LMO1 gene polymorphism susceptibility was further confirmed in five other epidemiological studies of different ethnicities [39-43]. Apart from neuroblastoma, LMO1 gene polymorphisms were also associated with acute lymphoblastic leukemia susceptibility. In Caucasian children (163 patients and 251 controls), Beuten et al. found an association between another genotype of the LMO1 gene (rs442264 A>G) and susceptibility to acute lymphocytic leukemia [44]. In addition, recent studies have indicated that in anti-EGFR therapy, overexpression of LMO1 may be a predictive marker for colorectal cancer [45], lung cancer [46] and prostate cancer [47].

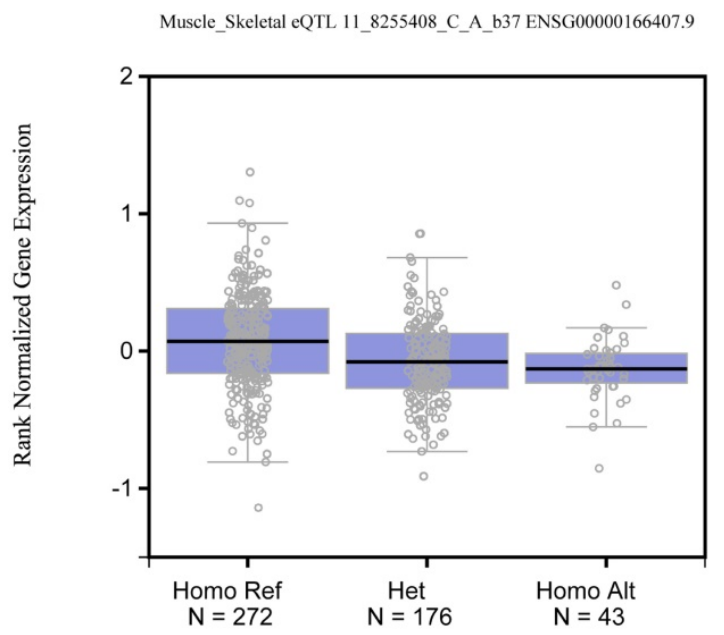

Figure 1. Expression quantitative trait loci (eQTL) analysis of $L M O I$ gene rs2168101 G>T. The genotypes of rs2168101 G>T was correlated to the expressions of LMOI gene in Skeletal Muscle tissues were searched based on the public database GTEx Portal (http://www.gtexportal.org/home/).

Table 2. Stratification analysis of risk genotypes with Wilms tumor susceptibility

\begin{tabular}{|c|c|c|c|c|c|c|c|c|c|c|c|c|}
\hline \multirow[t]{2}{*}{ Variables } & \multicolumn{2}{|c|}{$\begin{array}{l}\text { rs2168101 } \\
\text { (cases/controls) }\end{array}$} & \multirow[t]{2}{*}{$\begin{array}{l}\text { Adjusted OR a } \\
(95 \% \mathrm{CI})\end{array}$} & \multirow[t]{2}{*}{$P$ a } & \multicolumn{2}{|c|}{$\begin{array}{l}\text { rs2071458 } \\
\text { (cases/controls) }\end{array}$} & \multirow[t]{2}{*}{$\begin{array}{l}\text { Adjusted OR a } \\
(95 \% \mathrm{CI})\end{array}$} & \multirow[t]{2}{*}{$P$ a } & \multicolumn{2}{|c|}{$\begin{array}{l}\text { Combined genotypes } \\
\text { (cases/controls) }\end{array}$} & \multirow[t]{2}{*}{$\begin{array}{l}\text { Adjusted OR a } \\
(95 \% \mathrm{CI})\end{array}$} & \multirow[t]{2}{*}{$P$ a } \\
\hline & GG & GT/TT & & & $\mathrm{CC}$ & CA/AA & & & $0-2$ & $3-5$ & & \\
\hline \multicolumn{13}{|c|}{ Age, month } \\
\hline$\leq 18$ & $44 / 128$ & $22 / 105$ & $0.60(0.34-1.07)$ & 0.085 & $44 / 139$ & $22 / 94$ & $0.75(0.42-1.33)$ & 0.316 & $26 / 66$ & $40 / 167$ & $0.61(0.35-1.09)$ & 0.094 \\
\hline$>18$ & $46 / 147$ & $33 / 151$ & $0.70(0.42-1.15)$ & 0.157 & $57 / 185$ & $22 / 113$ & $0.64(0.37-1.10)$ & 0.104 & $29 / 80$ & $50 / 218$ & $0.62(0.37-1.06)$ & 0.079 \\
\hline \multicolumn{13}{|l|}{ Gender } \\
\hline Females & $36 / 126$ & $28 / 107$ & $0.93(0.53-1.62)$ & 0.793 & $51 / 136$ & $13 / 97$ & $0.36(0.19-0.70)$ & 0.003 & $24 / 57$ & $40 / 176$ & $0.55(0.30-0.99)$ & 0.045 \\
\hline Males & $54 / 149$ & $27 / 149$ & $0.50(0.30-0.84)$ & 0.009 & $50 / 188$ & $31 / 110$ & $1.08(0.65-1.80)$ & 0.760 & $31 / 89$ & $50 / 209$ & $0.71(0.42-1.18)$ & 0.188 \\
\hline \multicolumn{13}{|c|}{ Clinical stages } \\
\hline I & $3 / 275$ & $1 / 256$ & $0.37(0.04-3.57)$ & 0.387 & $3 / 324$ & $1 / 207$ & $0.61(0.06-6.02)$ & 0.673 & $2 / 146$ & $2 / 385$ & $0.45(0.06-3.29)$ & 0.432 \\
\hline II & $32 / 275$ & $17 / 256$ & $0.59(0.32-1.10)$ & 0.098 & $34 / 324$ & $15 / 207$ & $0.70(0.37-1.33)$ & 0.274 & $20 / 146$ & $29 / 385$ & $0.57(0.31-1.04)$ & 0.068 \\
\hline III & $27 / 275$ & $23 / 256$ & $0.91(0.51-1.63)$ & 0.758 & $38 / 324$ & $12 / 207$ & $0.49(0.25-0.96)$ & 0.038 & $22 / 146$ & $28 / 385$ & $0.47(0.26-0.86)$ & 0.014 \\
\hline IV & $21 / 275$ & $12 / 256$ & $0.60(0.29-1.25)$ & 0.175 & $21 / 324$ & $12 / 207$ & $0.91(0.44-1.88)$ & 0.789 & $8 / 146$ & $25 / 385$ & $1.22(0.53-2.77)$ & 0.642 \\
\hline I+II & $35 / 275$ & $18 / 256$ & $0.58(0.32-1.05)$ & 0.071 & $37 / 324$ & $16 / 207$ & $0.69(0.37-1.28)$ & 0.241 & $22 / 146$ & $31 / 385$ & $0.56(0.31-1.00)$ & 0.052 \\
\hline $\mathrm{III}+\mathrm{IV}$ & $48 / 275$ & $35 / 256$ & $0.78(0.49-1.24)$ & 0.294 & $59 / 324$ & $24 / 207$ & $0.63(0.38-1.05)$ & 0.078 & $30 / 146$ & $53 / 385$ & $0.67(0.41-1.09)$ & 0.108 \\
\hline
\end{tabular}


The associations of the LMO1 gene polymorphisms (rs110419 A>G, rs4758051 G>A, rs10840002 A>G and rs204938 A>G) with Wilms tumor susceptibility were reported in our previous study. Here, we performed a further study on the associations between five LMO1 gene polymorphisms (rs2168101 $\mathrm{G}>\mathrm{T}$, rs1042359 A>G, rs11041838 G>C, rs2071458 C>A and rs3750952 G>C) and Wilms tumor susceptibility in 145 patients and 531 healthy controls. We found that the GT/TT genotypes of the rs2168101 G>T polymorphism correspond to a significant decrease in Wilms tumor susceptibility, while we failed to detect significant associations between the other four polymorphisms and Wilms tumor susceptibility. The rs2168101 GT/TT genotypes carriers had a significantly decreased Wilms tumor risk. The protective effects of this SNP may be ascribed to the lower expression of LMO1 gene which is confirmed by Oldridge et al. [23] as well as data from GTEx database. Among these five polymorphisms we observed, the rs2168101 G>T polymorphism corresponded to a significant decrease in Wilms tumor susceptibility only for the rs2168101 GT carriers compared with the GG carriers, suggesting a protective effect of this polymorphism against Wilms tumor. There did not seem to be an association between the other four polymorphisms and Wilms tumor susceptibility. The relatively small sample size of this current study might have limited the statistical power for detecting a difference. Non-significant SNPs in the single locus analysis may collectively modify Wilms tumor susceptibility. Not surprisingly, the combined analysis indicated that 3-5 protective genotypes obviously decreased Wilms tumor susceptibility in females. However, there is still no direct evidence showing the exact association of LMO1 gene polymorphisms (rs2168101 G>T and rs2071458 C>A) with gender and clinical stage.

Several potential limitations of the current study may be ascribed to the following: 1) the relatively small sample size and lacking of multi-center clinical study, 2) the consideration of only five polymorphisms that lack potential function, and 3) the influence of environmental factors on Wilms tumor susceptibility.

In conclusion, we verified that the LMO1 super-enhancer rs2168101 G>T polymorphism was also significantly associated with a decreased risk of Wilms tumor.

\section{Abbreviations}

GWAS, genome-wide association study; LMO1, LIM domain only 1 ; OR, odds ratio; $\mathrm{CI}$, confidence interval.

\section{Supplementary Material}

Supplementary tables.

http://www.jcancer.org/v10p1808s1.pdf

\section{Acknowledgments}

This study was supported by grants from the National Natural Science Foundation of China (No: 81803320), Science and Technology Project of Guangzhou (No: 201804010037), and the Science and Technology Planning Project of Guangdong Province (No: 2016A020215009).

\section{Competing Interests}

The authors have declared that no competing interest exists.

\section{References}

1. Brok J, Treger TD, Gooskens SL, van den Heuvel-Eibrink MM, Pritchard-Jones K. Biology and treatment of renal tumours in childhood. Eur J Cancer. 2016; 68: 179-95.

2. Chu A, Heck JE, Ribeiro KB, Brennan P, Boffetta P, Buffler P, et al. Wilms' tumour: a systematic review of risk factors and meta-analysis. Paediatr Perinat Epidemiol. 2010; 24: 449-69.

3. Hohenstein P, Pritchard-Jones K, Charlton J. The yin and yang of kidney development and Wilms' tumors. Genes Dev. 2015; 29: 467-82.

4. Tian F, Yourek G, Shi X, Yang Y. The development of Wilms tumor: from WT1 and microRNA to animal models. Biochim Biophys Acta. 2014; 1846: 180-7.

5. Rivera MN, Haber DA. Wilms' tumour: connecting tumorigenesis and organ development in the kidney. Nat Rev Cancer. 2005; 5: 699-712.

6. Bao PP, Li K, Wu CX, Huang ZZ, Wang CF, Xiang YM, et al. [Recent incidences and trends of childhood malignant solid tumors in Shanghai, 2002-2010]. Zhonghua Er Ke Za Zhi. 2013; 51: 288-94.

7. Little SE, Hanks SP, King-Underwood L, Jones C, Rapley EA, Rahman N, et al. Frequency and heritability of WT1 mutations in nonsyndromic Wilms' tumor patients: a UK Children's Cancer Study Group Study. J Clin Oncol. 2004; 22: 4140-6.

8. Scott RH, Douglas J, Baskcomb L, Huxter N, Barker $\mathrm{K}$, Hanks S, et al. Constitutional 11p15 abnormalities, including heritable imprinting center mutations, cause nonsyndromic Wilms tumor. Nat Genet. 2008; 40: 1329-34.

9. Stadler ZK, Thom P, Robson ME, Weitzel JN, Kauff ND, Hurley KE, et al. Genome-wide association studies of cancer. J Clin Oncol. 2010; 28: 4255-67.

10. Rahman N, Arbour L, Tonin P, Renshaw J, Pelletier J, Baruchel S, et al. Evidence for a familial Wilms' tumour gene (FWT1) on chromosome 17q12-q21. Nat Genet. 1996; 13: 461-3.

11. Rapley EA, Barfoot R, Bonaiti-Pellie C, Chompret A, Foulkes W, Perusinghe $\mathrm{N}$, et al. Evidence for susceptibility genes to familial Wilms tumour in addition to WT1, FWT1 and FWT2. Br J Cancer. 2000; 83: 177-83.

12. Reid S, Renwick A, Seal S, Baskcomb L, Barfoot R, Jayatilake H, et al. Biallelic BRCA2 mutations are associated with multiple malignancies in childhood including familial Wilms tumour. J Med Genet. 2005; 42: 147-51.

13. Maschietto M, Williams RD, Chagtai T, Popov SD, Sebire NI, Vujanic G, et al. TP53 Mutational Status Is a Potential Marker for Risk Stratification in Wilms Tumour with Diffuse Anaplasia. PLoS One. 2016; 9: e109924.

14. Fu W, Zhuo ZJ, Jia W, Zhu J, Zhu SB, Lin ZF, et al. Association between TP53 gene Arg72Pro polymorphism and Wilms' tumor risk in a Chinese population. Onco Targets Ther. 2017; 10: 1149-54.

15. Fu W, Zhu J, Xiong SW, Jia W, Zhao Z, Zhu SB, et al. BARD1 Gene Polymorphisms Confer Nephroblastoma Susceptibility. EBioMedicine. 2017; 16: $101-5$.

16. Hanks S, Perdeaux ER, Seal S, Ruark E, Mahamdallie SS, Murray A, et al. Germline mutations in the PAF1 complex gene CTR9 predispose to Wilms tumour. Nat Commun. 2014; 5: 4398.

17. Zhu J, Jia W, Wu C, Fu W, Xia H, Liu G, et al. Base Excision Repair Gene Polymorphisms and Wilms Tumor Susceptibility. EBioMedicine. 2018; 33: 88-93.

18. Zhu J, Fu W, Jia W, Xia H, Liu GC, He J. Association between NER Pathway Gene Polymorphisms and Wilms Tumor Risk. Mol Ther Nucleic Acids. 2018; 12. 854-60.

19. He BS, Sun HL, Xu T, Pan YQ, Lin K, Gao TY, et al. Association of Genetic Polymorphisms in the LncRNAs with Gastric Cancer Risk in a Chinese Population. J Cancer. 2017; 8: 531-6.

20. Liu GC, Zhuo ZJ, Zhu SB, Zhu J, Jia W, Zhao Z, et al. Associations between LMO1 gene polymorphisms and Wilms' tumor susceptibility. Oncotarget. 2017; 8: 50665-72. 
21. Greenberg JM, Boehm T, Sofroniew MV, Keynes RJ, Barton SC, Norris ML, et al. Segmental and developmental regulation of a presumptive T-cell oncogene in the central nervous system. Nature. 1990; 344: 158-60.

22. Boehm T, Foroni L, Kaneko Y, Perutz MF, Rabbitts TH. The rhombotin family of cysteine-rich LIM-domain oncogenes: distinct members are involved in T-cell translocations to human chromosomes 11p15 and 11p13. Proc Natl Acad Sci U S A. 1991; 88: 4367-71.

23. Oldridge DA, Wood AC, Weichert-Leahey N, Crimmins I, Sussman R, Winter $\mathrm{C}$, et al. Genetic predisposition to neuroblastoma mediated by a LMO1 super-enhancer polymorphism. Nature. 2015; 528: 418-21.

24. Jia W, Deng Z, Zhu J, Fu W, Zhu S, Zhang LY, et al. Association Between HACE1 Gene Polymorphisms and Wilms' Tumor Risk in a Chinese Population. Cancer Invest. 2017; 35: 633-8.

25. Fu W, Li L, Xiong SW, Zhang T, Jia W, Zhu J, et al. miR-423 rs6505162 C>A polymorphism contributes to decreased Wilms tumor risk. J Cancer. 2018; 9: 2460-5.

26. Fu W, Liu GC, Zhao Z, Zhu J, Jia W, Zhu SB, et al. The correlation between LIN28B gene potentially functional variants and Wilms tumor susceptibility in Chinese children. J Clin Lab Anal. 2018; 32: e22200.

27. He J, Wang F, Zhu J, Zhang R, Yang T, Zou Y, et al. Association of potentially functional variants in the XPG gene with neuroblastoma risk in a Chinese population. J Cell Mol Med. 2016; 20: 1481-90.

28. He J, Yang T, Zhang R, Zhu J, Wang F, Zou Y, et al. Potentially functional polymorphisms in the LIN28B gene contribute to neuroblastoma susceptibility in Chinese children. J Cell Mol Med. 2016; 20: 1534-41.

29. He J, Zhang R, Zou Y, Zhu J, Yang T, Wang F, et al. Evaluation of GWAS-identified SNPs at $6 \mathrm{p} 22$ with neuroblastoma susceptibility in a Chinese population. Tumour Biol. 2016; 37: 1635-9.

30. He J, Wang F, Zhu J, Zhang Z, Zou Y, Zhang R, et al. The TP53 gene rs1042522 $\mathrm{C}>\mathrm{G}$ polymorphism and neuroblastoma risk in Chinese children. Aging (Albany NY). 2017; 9: 852-9.

31. He J, Zhang X, Zhang J, Zhang R, Yang T, Zhu J, et al. LMO1 super-enhancer polymorphism rs2168101 $\mathrm{G}>\mathrm{T}$ correlates with decreased neuroblastoma risk in Chinese children. J Cancer. 2018; 9: 1592-7.

32. He J, Qiu LX, Wang MY, Hua RX, Zhang RX, Yu HP, et al. Polymorphisms in the XPG gene and risk of gastric cancer in Chinese populations. Hum Genet. 2012; 131: 1235-44.

33. Chang J, Tian J, Yang Y, Zhong R, Li J, Zhai K, et al. A rare missense variant in TCF7L2 associates with colorectal cancer risk by interacting with a GWAS-identified regulatory variant in the MYC enhancer. Cancer Res. 2018; 78: 5164-5172.

34. Li J, Chang J, Tian J, Ke J, Zhu Y, Yang Y, et al. A Rare Variant P507L in TPP1 Interrupts TPP1-TIN2 Interaction, Influences Telomere Length, and Confers Colorectal Cancer Risk in Chinese Population. Cancer Epidemiol Biomarkers Prev. 2018; 27: 1029-1035.

35. Zou D, Lou J, Ke J, Mei S, Li J, Gong Y, et al. Integrative expression quantitative trait locus-based analysis of colorectal cancer identified a functional polymorphism regulating SLC22A5 expression. Eur J Cancer. 2018; 93. $1-9$.

36. Beckwith JB. National Wilms Tumor Study: an update for pathologists. Pediatric Dev Pathol. 1998; 1: 79-84.

37. Zhuo ZI, Liu W, Zhang J, Zhu J, Zhang R, Tang J, et al. Functional Polymorphisms at ERCC1/XPF Genes Confer Neuroblastoma Risk in Chinese Children. EBioMedicine. 2018; 30: 113-9.

38. Wang K, Diskin SJ, Zhang H, Attiyeh EF, Winter C, Hou C, et al. Integrative genomics identifies LMO1 as a neuroblastoma oncogene. Nature. 2011; 469: 216-20.

39. He J, Zhong $\mathrm{W}$, Zeng J, Zhu J, Zhang $\mathrm{R}$, Wang $\mathrm{F}$, et al. LMO1gene polymorphisms contribute to decreased neuroblastoma susceptibility in a Southern Chinese population. Oncotarget. 2016; 7: 22770-8.

40. Lu J, Chu P, Wang H, Jin Y, Han S, Han W, et al. Candidate Gene Association Analysis of Neuroblastoma in Chinese Children Strengthens the Role of LMO1. PLoS One. 2015; 10: e0127856.

41. Latorre V, Diskin SJ, Diamond MA, Zhang H, Hakonarson H, Maris JM, et al. Replication of neuroblastoma SNP association at the BARD1 locus in African-Americans. Cancer Epidemiol Biomarkers Prev. 2012; 21: 658-63.

42. Capasso M, Diskin SJ, Totaro F, Longo L, De Mariano M, Russo R, et al. Replication of GWAS-identified neuroblastoma risk loci strengthens the role of BARD1 and affirms the cumulative effect of genetic variations on disease susceptibility. Carcinogenesis. 2013; 34: 605-11.

43. Zhang J, Lin H, Wang J, He J, Zhang D, Qin P, et al. LMO1 polymorphisms reduce neuroblastoma risk in Chinese children: a two-center case-control study. Oncotarget. 2017; 8: 65620-6.

44. Beuten J, Gelfond JA, Piwkham D, Pollock BH, Winick NJ, Rd CA, et al. Candidate gene association analysis of acute lymphoblastic leukemia identifies new susceptibility locus at 11p15 (LMO1). Carcinogenesis. 2011; 32: 1349 .

45. Liu J, Yan P, Jing N, Yang J. LMO1 is a novel oncogene in colorectal cancer and its overexpression is a new predictive marker for anti-EGFR therapy. Tumour Biol. 2014; 31: 1-6.

46. Zhang Y, Yang J, Wang J, Guo H, Jing N. LMO1 is a novel oncogene in lung cancer, and its overexpression is a new predictive marker for anti-EGFR therapy. Med Oncol. 2014; 31: 99.
47. Gu H, Liu T, Cai X, Tong Y, Li Y, Wang C, et al. Upregulated LMO1 in prostate cancer acts as a novel coactivator of the androgen receptor. Int J Oncol. 2015; 47: 2181-2187. 